\title{
ON THE REGULARIZABILITY CONDITIONS OF INTEGRAL EQUATIONS
}

\author{
L.D. Menikhes, South Ural State University, Chelyabinsk, Russian Federation, \\ leonid.menikhes@gmail.com, \\ V.V. Karachik, South Ural State University, Chelyabinsk, Russian Federation, \\ karachik@susu.ru
}

Solving of integral equations of the first kind is an ill-posed problem. It is known that all problems can be divided into three disjoint classes: correct problems, ill-posed regularizable problems and ill-posed not regularizable problems. Problems of the first class are so good that no regularization method for them is needed. Problems of the third class are so bad that no one regularization method is applicable to them. A natural application field of the regularization method is the problems from the second class. But how to know that a particular integral equation belongs to the second class rather than to the third class? For this purpose a large number of sufficient regularizability conditions were constructed. In this article one infinite series of sufficient conditions for regularizability of integral equations constructed with the help of duality theory of Banach spaces is investigated. This method of constructing of sufficient conditions proved to be effective in solving of ill-posed problems. It is proved that these conditions are not pairwise equivalent even if we are restricted by the equations with the smooth symmetric kernels.

Keywords: integral equations; regularizability; smooth symmetric kernels.

To the memory of Alfredo Lorenzi.

\section{Introduction}

In 1963 a new method for solving of ill-posed problems called as regularization method was proposed by A.N. Tikhonov [1]. The subsequent development of the science has shown a great efficiency of the regularization method. However, soon it became clear that this method does not provide a satisfactory solution in all cases. Problems for which there is a convergence of the regularization method became known as regularizable problems. Thus all ill-posed problems can be divided into two classes: regularizable problems and non-regularizable problems. In [2] an example of the non-regularizable integral equation was constructed. So, finding conditions for the regularizability of a problem is an important and actual problem. In papers [3-8] using the duality theory of Banach spaces the regularizability conditions were investigated. In paper [9] integro-differential equations were considered and in paper [10] some multidimensional integral equations were investigated.

\section{Sufficient Regularizability Conditions of Integral Equations}

Let $E$ and $F$ be Banach spaces and $A: E \rightarrow F$ be a linear continuous injective operator.

Definition 1. Mapping $A^{-1}$ is called a regularizable if there exists a family of mappings $R_{\delta}$ : $F \rightarrow E$, where $\delta \in\left(0, \delta_{0}\right)$ such that

$$
\lim _{\delta \rightarrow 0} \sup _{y:\|y-A x\| \leq \delta}\left\|R_{\delta} y-x\right\|=0
$$

for any $x \in E$. 
In this case, a family of operators $\left\{R_{\delta}\right\}$ is called a regularizer for the operator $A^{-1}$. The operator equation $A x=y$ is called a regularizable equation, if the mapping $A^{-1}$ is a regularizable mapping. In this case a family of elements $\left\{x_{\delta}=R_{\delta} y_{\delta}\right\}$ gives a satisfactory approximate solution to the problem of finding of a solution to the operator equation $A x=y$ when a right-hand side $y_{\delta}$ of this equation is given approximately with a precision $\delta$.

Consider the classical situation when $E=C(0,1)$ and $F=L_{2}(0,1)$. Assume that the operator $A$ is also continuous in the $L_{2}$-norm. Then the operator $A$ can be extended by continuity to the various subspaces $M$ such that $C(0,1) \subset M \subset L_{2}(0,1)$.

In the papers $[4,5]$ the following theorems giving some sufficient conditions for the regularizability are proved.

Theorem 1. If the integral operator $A: C(0,1) \rightarrow L_{2}(0,1)$ is injective and its extension to some $L_{p}(0,1), p \geq 2$ has a finite-dimensional kernel, then the mapping $A^{-1}$ is regularizable.

Theorem 2. If the integral operator $A: C(0,1) \rightarrow L_{2}(0,1)$ is injective and its extension to $L_{\infty}(0,1)$ has a finite-dimensional kernel, then the mapping $A^{-1}$ is regularizable.

Theorem 3. If the integral operator $A: C(0,1) \rightarrow L_{2}(0,1)$ is injective and its extension to $\bigcap_{p \geq 2} L_{p}(0,1)$ has a finite-dimensional kernel, then the mapping $A^{-1}$ is regularizable.

Thus we have an infinite series of regularizability conditions for the integral equations at various values of $p \geq 2$. The question arises here: are any of these conditions equivalent, if the integral operators with the smooth symmetric kernels are considered? In paper [6] the negative answer for all conditions from Theorem 1 is given. All these conditions are not pairwise equivalent. In paper [7] it is proved that any condition from Theorem 1 is not equivalent to the condition from Theorem 2. The question about equivalence of conditions from Theorems 1 and 3 , and conditions from Theorems 2 and 3 remains open. In the next section a negative answer to this question is given.

\section{Comparison of Regularizability Conditions}

Consider the integral operator

$$
Q: f(x) \rightarrow \int_{0}^{1} K(x, t) f(t) d t
$$

acting from $C(0,1)$ to $L_{2}(0,1)$. Let $K(x, t)$ be a continuous function on the unit square $[0,1] \times[0,1]$. Then the operator $Q$ is also continuous according to $L_{2}$-norm in $C(0,1)$. Let us denote by $\bar{Q}$ an extension of the operator $Q$ to $L_{2}(0,1)$. The operator $Q$ is assumed to be injective, as we investigate the regularizability of $Q^{-1}$. However, the operator $\bar{Q}$ is not necessarily be injective. Moreover, in the given above theorems a connection between $\operatorname{ker} \bar{Q}$ and regularizability of mapping $Q^{-1}$ is established.

Theorem 4. There exists an injective integral operator acting from $C(0,1)$ to $L_{2}(0,1)$ with the smooth symmetric kernel, extension of which to any $L_{p}(0,1), p \geq 2$ has an infinite-dimensional kernel and extension to $\bigcap_{p \geq 2} L_{p}(0,1)$ has a finite-dimensional kernel.

Proof. Integral operator $Q$ constructed in the proof of Theorem 3 from [7] satisfies all conditions and the statement of Theorem 4 . This is easy to see by looking at the corresponding proof.

Corollary 1. The sufficient regularizability conditions from Theorems 1 and 3 are not equivalent. 
Proof. Indeed, for the operator from Theorem 4 by virtue of Theorem 3 it follows the regularizability of mapping $A^{-1}$, while Theorem 1 does not give an answer about its regularizability.

Theorem 5. There exists an injective integral operator acting from $C(0,1)$ to $L_{2}(0,1)$ with the smooth symmetric kernel, extension of which to $\bigcap_{p \geq 2} L_{p}(0,1)$ has an infinite-dimensional kernel, but its extension to $L_{\infty}(0,1)$ has a finite-dimensional kernel.

Proof. Let us introduce a sequence of the intervals

$$
J_{k}=\left[1-\frac{1}{2^{k}}, 1-\frac{1}{2^{k+1}}\right], \quad k \in \mathbb{N} .
$$

We denote by $h_{k}(x)$ the functions defined on $[0,1]$ having the support in $J_{k}$ and such that

$$
h_{k}(x) \in \bigcap_{p \geq 2} L_{p}(0,1)
$$

but $h_{k}(x) \notin L_{\infty}(0,1)$ for $k \in \mathbb{N}$. It is easy to see that such functions exist. Indeed,

$$
\ln x \in \bigcap_{p \geq 2} L_{p}(0,1)
$$

since the integral

$$
\int_{0}^{1}|\ln x|^{p} d x
$$

converges for any $p \geq 2$, but $\ln x \notin L_{\infty}(0,1)$. If we now linearly mapping the interval $[0,1]$ on the internal $J_{k}$ then the function $\ln x$ transforms to a function which satisfies all conditions required from the function $h_{k}(x)$.

Denote by $M$ a closure of the linear span of functions $h_{k}(x)$

$$
M=\overline{\operatorname{span}\left\{h_{k}(x): k \in \mathbb{N}\right\}},
$$

i.e. the smallest closed subspace from $L_{2}(0,1)$ containing all the functions $h_{k}(x)$ for $k \in \mathbb{N}$. As usual $C_{0}^{\infty}(a, b)$ is a subspace of $C^{\infty}(a, b)$ consisting of functions with a compact support, i.e. infinitely differentiable and vanish in neighborhoods of the points $a$ and $b$.

Consider the following lemma from [2].

Lemma 1. Let $h(t) \in L_{2}(a, b)$ and

$$
H=\left\{f(t) \in L_{2}(a, b): \int_{a}^{b} f(t) h(t) d t=0\right\} .
$$

Then

$$
\overline{H \bigcap C_{0}^{\infty}(a, b)}=H .
$$

Let us verify that the functions from $C_{0}^{\infty}(a, b)$ are dense not only in the hyperplanes, but also in $N=M^{\perp}$, which is an orthogonal complement to $M$, i.e. the following equality

$$
\overline{N \bigcap C_{0}^{\infty}(0,1)}=N
$$

holds. 
Let $f \in N$ and $\varepsilon>0$. We show that there exists a function from $C_{0}^{\infty}(0,1) \cap N$ and such that $\|f-g\|<\varepsilon$. Choose a number $n$ such that

$$
\int_{1-\frac{1}{2^{n+1}}}^{1} f^{2}(t) d t \leq \frac{\varepsilon^{2}}{4} .
$$

Since the function $f(t)$ is orthogonal to the functions $h_{k}(t), k \in \mathbb{N}$, by virtue of Lemma 1 applied to the function $h_{k}(t)$ there exists a family of functions $\left\{f_{k}(t), k=1,2, \ldots, n\right\}$ for which the following conditions are fulfilled

$$
\begin{array}{lll}
\text { 1. } & f_{k}(t) \in C_{0}^{\infty}\left(J_{k}\right), & k=1,2, \ldots, n ; \\
\text { 2. } & \int_{J_{k}} f_{k}(t) h_{k}(t) d t=0, & k=1,2, \ldots, n \\
\text { 3. } & \left\|f_{k}-\left.f\right|_{J_{k}}\right\| \leq \frac{\varepsilon}{2(n+1)}, & k=1,2, \ldots, n
\end{array}
$$

where $\left.f\right|_{J_{k}}$ is a restriction of the function $f(t)$ on the interval $J_{k}$. Besides, there exists a function $f_{0}(t) \in C_{0}^{\infty}\left(0, \frac{1}{2}\right)$ in the interval $J_{0}=\left[0, \frac{1}{2}\right]$ such that

$$
\left\|f_{0}-\left.f\right|_{J_{0}}\right\| \leq \frac{\varepsilon}{2(n+1)}
$$

Now consider the function

$$
g(t)= \begin{cases}f_{k}(t), & \text { for } t \in J_{k}, k=0,1, \ldots, n \\ 0, & \text { for } t \in\left[1-\frac{1}{2^{n+1}}, 1\right]\end{cases}
$$

Using (4) we obtain that $g \in C_{0}^{\infty}(0,1) \cap N$ since for any $k \in \mathbb{N}$

$$
\int_{0}^{1} g(t) h_{k}(t) d t=\int_{J_{k}} g(t) h_{k}(t) d t=0,
$$

and therefore, for any $m(t) \in M$ we get

$$
\int_{0}^{1} g(t) m(t) d t=0
$$

Finally, because of (3), (4) and (5) and from the following relation

$$
\begin{aligned}
\|g-f\|=\sqrt{\int_{0}^{1}(g(t)-f(t))^{2} d t} & \leq \sqrt{\sum_{k=0}^{n} \int_{J_{k}}(g(t)-f(t))^{2} d t+\frac{\varepsilon^{2}}{4}} \leq \\
& \leq \sum_{k=0}^{n} \sqrt{\int_{J_{k}}(g(t)-f(t))^{2} d t}+\frac{\varepsilon}{2} \leq \sum_{k=0}^{n} \frac{\varepsilon}{2(n+1)}+\frac{\varepsilon}{2}=\varepsilon
\end{aligned}
$$

it follows that $\overline{N \bigcap C_{0}^{\infty}(0,1)}=N$.

Further, from (2) it follows that in $N$ there exists a complete orthonormal system of functions $\left\{\psi_{n}(t)\right\}$ belonging to $C_{0}^{\infty}(0,1)$. It is true because we are able to choose a full linearly independent sequence of functions from $N \cap C_{0}^{\infty}(0,1)$, orthogonalization of which gives us the necessary system of functions $\left\{\psi_{n}(t)\right\}$. 
Now consider the integral operator $Q$, given by formula (1) with the kernel of the form

$$
K(x, t)=\sum_{n=1}^{\infty} a_{n} \varphi_{n}(x) \psi_{n}(t)
$$

where $\left\{\varphi_{n}(x)\right\}$ is an arbitrary orthonormal system of infinitely differentiable functions on $[0,1]$, $\left\{\psi_{n}(t)\right\}$ is the constructed above system of functions and

$$
\begin{aligned}
& a_{n}=\frac{1}{n^{2}}\left(\max \left(\sup _{x \in[0,1]}\left|\varphi_{n}(x)\right|, \ldots, \sup _{x \in[0,1]}\left|\varphi_{n}^{(n)}(x)\right|\right)\right)^{-1} \times \\
& \times\left(\max \left(\sup _{t \in[0,1]}\left|\psi_{n}(t)\right|, \ldots, \sup _{t \in[0,1]}\left|\psi_{n}^{(n)}(t)\right|\right)\right)^{-1} .
\end{aligned}
$$

Then it is clear that the series from (6) converges uniformly and the series obtained from it by any-times termwise differentiation are also converges uniformly. Therefore the function $K(x, t)$ is an infinitely differentiable function on the unit square $[0,1] \times[0,1]$.

We show that $\operatorname{ker} \bar{Q}=M$. In fact, if

$$
\int_{0}^{1} K(x, t) f(t) d t=\int_{0}^{1} \sum_{n=1}^{\infty} a_{n} \varphi_{n}(x) \psi_{n}(t) f(t) d t=0
$$

then

$$
\sum_{n=1}^{\infty} a_{n} b_{n} \varphi_{n}(x)=0
$$

where

$$
b_{n}=\int_{0}^{1} f(t) \psi_{n}(t) d t
$$

is the $n$-th Fourier coefficient of function $f(t)$ by the system of functions $\left\{\psi_{n}(t)\right\}$. According to the Lebesgue theorem the series from (7) can be integrated term by term. From (8), since the system $\left\{\varphi_{n}(x)\right\}$ is orthonormal and $a_{n} \neq 0$, it follows that $b_{n}=0$ for $n \in \mathbb{N}$, i.e. $f(t) \in N^{\perp}=M$. It is obvious that if $f(t) \in M$ then $f(t) \in \operatorname{ker} \bar{Q}$.

So, we proved that $\operatorname{ker} \bar{Q}=M$. If we take $\varphi_{n}=\psi_{n}$, then the kernel of the operator $Q$ is symmetric. It follows that the operator $Q$ satisfies all conditions and statement of the theorem. Indeed, operator $Q$ is an integral operator with a smooth symmetric kernel, it is injective on $C(0,1)$, since all the functions in $M$, except the identical zero, are discontinuous. Its extension to $\bigcap_{p \geq 2} L_{p}(0,1)$ has an infinite-dimensional kernel because it contains all the functions $h_{k}(t), k \in \mathbb{N}$. But extension of the operator $Q$ to $L_{\infty}(0,1)$ has a null kernel because all the functions in $M$, except identical zero, are not bounded. Theorem is proved.

Corollary 2. Sufficient regularizability conditions from Theorems 2 and 3 are not equivalent.

Proof. In fact, for the operator $Q$ constructed in Theorem 5, from Theorem 2 it follows the regularizability of $Q^{-1}$, while Theorem 3 does not give an answer about regularizability of $Q^{-1}$. 


\title{
References
}

1. Tikhonov A.N. [The Solution of Incorrectly Formulated Problems and the Regularization Method]. Dokl. AN SSSR, 1963, vol. 151, no. 3, pp. 501-504. (in Russian)

2. Menikhes L.D. [Regularizability of Mappings of Inverse to Integral Operators]. Dokl. AN SSSR, 1978, vol. 241, no. 2, pp. 282-285. (in Russian)

3. Vinokurov V.A., Menikhes L.D. [Necessary and Sufficient Condition for the Linear Regularizability]. Dokl. AN SSSR, 1976, vol. 229, no. 6, pp. 1292-1294. (in Russian)

4. Menikhes L.D. Regularizability of Some Classes of Mappings That are Inverses of Integral Operators. Mathematical Notes, 1999, vol. 65, no. 1-2, pp. 181-187. DOI: 10.1007/BF02679815

5. Menikhes L.D. On a Sufficient Condition for Regularizability of Linear Inverse Problems. Mathematical Notes, 2007, vol. 82, no. 1-2, pp. 242-246. DOI: 10.1134/S0001434607070267

6. Menikhes L.D., Kondrat'eva O.A. On Comparison of the Conditions for Regularizability of Integral Equations. Izvestiya Chelyabinskogo Nauchnogo Centra, 2009, vol. 1 (43), pp. 11-15. (in Russian)

7. Menikhes L.D. On Connection Between Sufficient Conditions of Regularizability of Integral Equations. Bulletin of the South Ural State University. Series: Mathematics. Mechanics. Physics, 2013, vol. 5, no. 1, pp. 50-54. (in Russian)

8. Menikhes L.D. Linear Regularizability of Mappings Inverse to Linear Operators. Russian Mathematics, 1979, no. 12, pp. 35-38. (in Russian)

9. Favini A., Lorenzi A., Tanabe H. Singular Evolution Integro-Differential Equations with Kernels Defined on Bounded Intervals. Applicable Analysis, 2005, vol. 84, no. 5, pp. 463-497. DOI: $10.1080 / 00036810410001724418$

10. Karachik V.V. Normalized System of Functions with Respect to the Laplace Operator and Its Applications. Journal of Mathematical Analysis and Applications, 2003, vol. 287, no. 2, pp. 577-592. DOI: 10.1016/S0022-247X(03)00583-3

\section{ОБ УСЛОВИЯХ РЕГУЛЯРИЗУЕМОСТИ ИНТЕГРАЛЬНЫХ УРАВНЕНИЙ}

\author{
Л.Д. Менихес, В.в. Карачик
}

Решение интегральных уравнений первого рода представляет собой некорректную задачу. Как известно, все задачи можно разбить на три непересекающихся класса: корректные задачи, некорректные регуляризуемые задачи, некорректные нерегуляризуемые задачи. Задачи из первого класса настолько хороши, что метод регуляризации для них не нужен. Задачи третьего класса настолько плохи, что метод регуляризации к ним не применим. Естественным полем применения метода регуляризации являются 
задачи второго класса. Но как узнать, что данное интегральное уравнение принадлежит ко второму, а не к третьему классу. Для этого было построено большое количество достаточных условий регуляризуемости. В данной статье исследуется одна бесконечная серия достаточньх условий регуляризуемости интегральных уравнений, построенных с помощью теории двойственности банаховых пространств. Этот метод построения достаточных условий показал свою эффективность при решении некорректных задач. Доказано, что эти условия являются попарно не эквивалентными, даже если ограничиться уравнениями с гладкими симметричными ядрами.

Ключевые слова: интегральные уравнения; регуляризуемость; гладкие симметричные ядра.

\section{Литература}

1. Тихонов, А.Н. О решении некорректно поставленных задач и методе регуляризации / А.Н. Тихонов // Докл. АН СССР. - 1963. - Т.‘151, № 3. - С. 501-504.

2. Менихес, Л.Д. О регуляризуемости отображений, обратных к интегральным операторам / Л.Д. Менихес // Докл. АН СССР. - 1978. - Т. 241, № 2. - С. 282-285.

3. Винокуров, В.А. Необходимое и достаточное условие линейной регуляризуемости / В.А. Винокуров, Л.Д. Менихес // Докл. АН СССР. - 1976. - Т. 229, № 6. - С. 1292-1294.

4. Менихес, Л.Д. О регуляризуемости некоторых классов отображений, обратных к интегральным операторам / Л.Д. Менихес // Математические заметки. - 1999. - Т. 65, № 2 . - C. $222-229$.

5. Менихес, Л.Д. Об одном достаточном условии регуляризуемости линейных обратных задач / Л.Д. Менихес // Математические заметки. - 2007. - Т. 82, № 2. - С. 242-247.

6. Менихес, Л.Д. О сравнении условий регуляризуемости интегральных уравнений Л.Д. Менихес, О.А. Кондратьева // Известия Челябинского научного центра. - 2009. Вып. 1 (43). - С. 11-15.

7. Менихес, Л.Д. О связи достаточных условий регуляризуемости интегральных уравнений / Л.Д. Менихес // Вестник Южно-Уральского государственного университета. Серия: Математика. Механика. Физика. - 2013. - Т. 5, № 1. - С. 50-54.

8. Менихес, Л.Д. Линейная регуляризуемость отображений, обратных к линейным операторам / Л.Д. Менихес // Известия высших учебных заведений. Математика. - 1979. № 12. - С. 35-38,

9. Favini, A. Singular Evolution Integro-Differential Equations with Kernels Defined on Bounded Intervals / A. Favini, A. Lorenzi, H. Tanabe // Applicable Analysis. - 2005. - V. 84, № 5. P. $463-497$.

10. Karachik, V.V. Normalized System of Functions with Respect to the Laplace Operator and Its Applications / V.V. Karachik // Journal of Mathematical Analysis and Applications. 2003. - V. 287, № 2. - P. 577-592.

Леонид Давидович Менихес, доктор физико-математических наук, заведующий кафедрой, кафедра «Математический и функциональный анализ», Южно-Уральский государственный университет (г. Челябинск, Российская Федерация), leonid.menikhes@gmail.com.

Валерий Валентинович Карачик, доктор физико-математических наук, профессор, кафедра «Математический и функциональный анализ», Южно-Уральский государственный университет (г. Челябинск, Российская Федерация), karachik@susu.ru.

Поступила в редакиию 15 мая 2015 г.

Вестник ЮУрГУ. Серия «Математическое моделирование

и программирование» (Вестник ЮУрГУ ММП). 2015. Т. 8, № 3. С. 141-147 